Jurnal Media Pertanian Vol. 2 No. 1 Tahun 2017 Hal. 1 - 9

Media Komunikasi Hasil Penelitian dan Review Literatur Bidang Ilmu Agronomi ISSN $2503-1279$

\title{
TINGKAT SERANGAN HAMA UTAMA DAN PRODUKSI KOPI LIBERIKA TUNGKAL KOMPOSIT (Coffea SP.) DI KECAMATAN BETARA KABUPATEN TANJUNG JABUNG BARAT
}

\author{
Araz Meiln $^{1 *}$, Nasamsir ${ }^{1}$ dan Sugeng Riyanto ${ }^{2}$ \\ ${ }^{1}$ Program Studi Agroteknologi, Fakultas Pertanian Universitas Batanghari \\ J1. Slamet Riyadi, Broni Jambi. 36122. Telp. +62074160103 \\ ${ }^{2}$ Alumni Program Studi Agroteknologi, Fakultas Pertanian Universitas Batanghari \\ J1. Slamet Riyadi, Broni Jambi. 36122. Telp. +62074160103 \\ *email korespondensi : araz_meilin@yahoo.com
}

\begin{abstract}
This research aimed to know the main pest type and production of "liberika tungkal komposit (libtukom)" coffea plant (coffea sp.) in Betara District, West "Tanjung Jabung. "Regency. This research was conducted in August to September 2016 at three villages e.g. Parit Tomo, Serdang Jaya, and Parit Panglong and two districts e.g. Mekar Jaya, and Betara. Survey method was used in this research by observing the farmer that managed their " libtukom" coffee farming. The data collected were primary and secondary data. This experiment result showed that the main pests type of "libtukom" coffee plant is "hypothenemus hampei" insect pest. Average intensity of attacks in the three research areas is $10.33 \%$ or it's around $9.11 \%$ to $10.80 \%$. While "libtukom" coffee production and its productivity in the three research areas is 0,66 ton ha ${ }^{-1}$ year ${ }^{-1}$ to 0,67 ton hal $^{-1}$ year ${ }^{-1}$.

Keywords : main pest, intensity of attacks, liberika tungkal coffea.
\end{abstract}

\begin{abstract}
Abstrak
Penelitian ini bertujuan untuk mengetahui jenis hama utama dan produksi tanaman kopi liberika tungkal komposit (libtukom) (coffea sp.) di kecamatan Betara kabupaten Tanjung Jabung Barat. Penelitian ini dilaksanakan pada bulan Agustus sampai September 2016 di Desa Parit Tomo, Serdang Jaya dan Parit Panglong, Kelurahan Mekar Jaya, Betara. Metode pengumpulan data pada penelitian ini menggunakan metode survei. Survei dilakukan pada petani sampel yang melakukan usaha tanaman kopi "libtukom". Data yang dikumpulkan adalah data primer dan data sekunder. Hasil penelitian menyimpulkan bahwa jenis hama utama yang menyerang tanaman kopi "libtukom" di daerah penelitian adalah hama jenis serangga hypothenemus hampei. Rata-rata intensitas serangan di tiga daerah penelitian sebesar 10,33\% atau berkisar antara 9,11\% - 10,80\%. Sedangkan produksi dan produktivitas kopi "libtukom" di tiga daerah penelitian masing-masing berkisar antara 0,66 ton ha $^{-1} \operatorname{tahun}^{-1}$ sampai 0,67 ton ha tahun $^{-1}$.

Kata kunci : hama utama, tingkat serangan, kopi liberika tungkal
\end{abstract}

\section{PENDAHULUAN}

Kopi merupakan salah satu hasil komoditi perkebunan yang memiliki nilai ekonomis yang cukup tinggi diantara tanaman perkebunan lainnya dan berperan penting sebagai sumber devisa negara. Kopi tidak hanya berperan penting sebagai sumber devisa melainkan juga merupakan sumber penghasilan bagi tidak kurang dari satu setengah juta jiwa petani kopi di Indonesia (Rahardjo, 2013) 
Jurnal Media Pertanian Vol. 2 No. 1 Tahun 2017 Hal. 1 - 9

Media Komunikasi Hasil Penelitian dan Review Literatur Bidang Ilmu Agronomi ISSN $2503-1279$

Indonesia adalah produsen kopi terbesar ketiga di dunia setelah Brazil dan Vietnam dengan menyumbang sekitar 6\% dari produksi total kopi dunia dan Indonesia merupakan pengekspor kopi terbesar keempat dunia dengan pangsa pasar sekitar $11 \%$ di dunia (Raharjo, 2013). Produksi kopi Indonesia disumbangkan oleh tiga komponen yakni produksi kopi dari perkebunan rakyat, negara dan swasta. Pada tahun 2013 total produksi kopi Indonesia sebesar 675.881 ton dan lebih dari 95\% berasal dari perkebunan rakyat, produksi kopi jenis Robusta sebesar 509.557 ton dan Arabika sebesar 166.325 ton (Dirjen Perkebunan, 2014).

Kopi Liberika Tungkal Komposit (Libtukom) merupakan tanaman kopi yang berasal dari kabupaten Tanjung Jabung Barat dan telah ditetapkan sebagai varietas bina melalui Keputusan Menteri Pertanian Republik Indonesia No. 4968/Kpts/SR.120/12/2013 tanggal 6 Desember 2013.

Tabel 1. Produksi dan Luasan lahan kopi Liberika Tungkal Komposit (Libtukom) Kecamatan Betara Kabupaten Tanjung Jabung Barat Provinsi Jambi

\begin{tabular}{cccc}
\hline No & Tahun & Produksi (ton) & Luasan (ha) \\
\hline 1 & 2010 & 718,8 & 1.482 \\
2 & 2011 & 728,8 & 1.482 \\
3 & 2012 & 729,0 & 1.532 \\
4 & 2013 & 1.084 & 1.636 \\
5 & 2014 & 819,0 & 1.637 \\
\hline
\end{tabular}

Sumber: BPS Provinsi Jambi, 2014

Produksi kopi provinsi Jambi tahun 2013 sebesar 13.326 ton yang berasal dari perkebunan rakyat. Produksi kopi jenis Robusta sebesar 13.209 ton dan Arabika sebesar 117 ton (Dirjen Perkebunan, 2014). Produksi kopi Liberika Tungkal Komposit (Libtukom) provinsi Jambi, khususnya untuk kabupaten Tanjung Jabung Barat kecamatan Betara pada tahun 2010 sampai tahun 2014 disajikan pada Tabel 1. Produksi kopi Libtukom tertinggi pada tahun 2013 sebesar 1.084 ton dan mengalami penurunan pada tahun 2014 dengan total produksi sebesar 819 ton.

Kopi Libtukom memiliki ciri khas cita-rasa, buah dan daun berbeda dengan kopi Robusta atau Arabika serta mampu beradaptasi baik di lahan gambut dengan tanaman penaung pohon Pinang. Kopi Libtukom yang dikembangkan memiliki keunggulan yakni daya adaptasinya pada lahan gambut dan harga pasar yang sangat menjanjikan. Permintaan dari Malaysia mencapai harga Rp 33.000,-per kg di tingkat petani, melebihi harga kopi robusta yang berada dikisaran harga Rp. 16.000,-per kg (Dirjen Perkebunan. 2014). Potensi produksi kopi Libtukom rata-rata 909 gram kopi biji per pohon atau setara dengan $950 \mathrm{~kg}$ biji untuk penanaman dengan populasi 900-1.000 pohon per ha.

Sentra produksi utama kopi Libtukom di kecamatan Betara ada tiga, yakni kelurahan Serdang Jaya, Parit Tomo dan Parit Panglong. Kelurahan Serdang Jaya memiliki luas wilayah sebesar $119 \mathrm{~km}^{2}$ dengan luas kawasan penanaman kopi sebesar 40 ha dan jumlah pohon kopi dalam kawasan tersebut sebanyak 34.000 pohon dengan rata-rata pohon kopi per hektarnya sebesar 800-900 pohon. Di kelurahan Parit Tomo, total luasan tanam kopi Libtukom sebesar 151 ha dengan total pohon kopi dalam kawasan tersebut sebanyak 108.901 pohon, kelurahan Parit Panglong total luasan tanam kopi Libtukom seluas 85 ha dengan jumlah pohon kopi sebanyak 72.250 pohon.

Hama tanaman adalah organisme yang menyerang tanaman sehingga pertumbuhan dan perkembangannya terganggu. Secara morfologi ada beberapa bagian 
Jurnal Media Pertanian Vol. 2 No. 1 Tahun 2017 Hal. 1 - 9

Media Komunikasi Hasil Penelitian dan Review Literatur Bidang Ilmu Agronomi ISSN $2503-1279$

dari tanaman kopi yang biasa diserang oleh hama antara lain bagian buah kopi dikenal dengan penggerak buah kopi (PBKo) yang banyak disebabkan oleh serangga dari golongan kumbang (Hypothenemus hampei), bagian percabangan atau biasa disebut hama penggerek cabang yang banyak disebabkan oleh kumbang kecil (Xylosandrus spp), kutu hijau (Coccus viridis), kutu putih (Ferrisia virgata), bagian batang kopi yang biasa disebut hama penggerek batang kopi, banyak disebabkan oleh ulat (Zeuzera coffeae), hama pada akar seperti Nematoda (Pratylenchus coffeae) (Departemen Pertanian, 2002).

Buah kopi merupakan bagian terpenting dalam produksi kopi, selain itu buah kopi juga merupakan bagian yang paling sering ditemukan terserang hama. Hama yang menyerang yaitu Hypothenemus hampei. Hypothenemus hampei menyerang buah dengan endosperma yang telah mengeras, namun buah yang belum mengeras dapat juga diserang. Buah kopi yang bijinya masih lunak umumnya hanya digerek untuk mendapatkan makanan dan selanjutnya ditinggalkan. Buah demikian tidak berkembang, warnanya berubah menjadi kuning kemerahan dan akhirnya gugur. Serangan pada buah yang bijinya telah mengeras akan berakibat penurunan mutu kopi karena biji berlubang. Biji berlubang merupakan salah satu penyebab utama kerusakan mutu fisik, sedangkan cita rasa kopi dipengaruhi oleh kombinasi komponen-komponen senyawa kimia yang terkandung dalam biji (Tobing, Bakti, Sutanto dan Saragih,2006).

Hama penggerek buah kopi (PBKo, Hypothenemus hampei) (Coleoptera: Curculionidae) merupakan hama utama yang sangat merusak pada budidaya kopi di seluruh dunia, kecuali di Hawaii, Nepal dan Papua New Guinea (PNG) yang masih terbebas dari serangan hama tersebut sampai tahun 2009 (Vega et al., 2009). Kerugian akibat hama ini di dunia mencapai 500 juta USD setiap tahunnya (Vega et al., 2002). Di Indonesia, diperkirakan kerugian oleh hama PBKo mencapai 6,7 juta dolar AS per tahun (Wiryadiputra, 2007). Kerugian ini belum termasuk penurunan mutu yang berakibat juga pada penurunan harga (Wiryadiputra, 2012).

Hama penggerek buah kopi jenis $H$. hampei berkembang dengan bermetamorfosa sempurna dimulai pada tahapan telur, larva, pupa dan imago atau serangga dewasa. Ukuran tubuh kumbang betina lebih besar dari kumbang jantan. Panjang kumbang betina lebih kurang 1,7 mm dan lebar 0,7 mm, sedangkan panjang kumbang jantan 1,2 $\mathrm{mm}$ dan lebar 0,6-0,7 mm. Kumbang betina yang akan bertelur membuat lubang gerekan dengan diameter lebih kurang $1 \mathrm{~mm}$ pada buah kopi dan biasanya pada bagian ujung. Kemudian kumbang tersebut bertelur pada lubang yang dibuatnya. Telur menetas 5-9 hari. Stadium larva 10-26 hari dan stadium pupa 4-9 hari. Pada umumnya $H$. hampei menyerang buah dengan endosperma yang telah mengeras, namun buah yang belum mengeras dapat juga diserang. Buah kopi yang bijinya masih lunak umumnya hanya digerek untuk mendapatkan makanan dan selanjutnya ditinggalkan. Buah demikian tidak berkembang, warnanya berubah menjadi kuning kemerahan dan akhirnya gugur.

Serangan pada buah yang bijinya telah mengeras akan berakibat penurunan mutu kopi karena biji berlubang. Biji kopi yang cacat sangat berpengaruh negatif terhadap susunan senyawa kimianya, terutama pada kafein dan gula pereduksi. Biji berlubang merupakan salah satu penyebab utama kerusakan mutu kimia, sedangkan citarasa kopi dipengaruhi oleh kombinasi komponen-komponen senyawa kimia yang terkandung dalam biji (Tobing et al.,2006). Serangga $H$. hampei masuk ke dalam buah kopi dengan cara membuat lubang di sekitar diskus. Serangan pada buah muda menyebabkan gugur 
Jurnal Media Pertanian Vol. 2 No. 1 Tahun 2017 Hal. 1 - 9

Media Komunikasi Hasil Penelitian dan Review Literatur Bidang Ilmu Agronomi ISSN $2503-1279$

buah, serangan pada buah yang cukup tua menyebabkan biji kopi cacat berlubanglubang dan bermutu rendah (PPKKI, 2006).

Perkembangan $H$. hampei dipengaruhi oleh suhu dan ketersediaan buah kopi. $H$. hampei dapat hidup pada suhu $15^{\circ} \mathrm{C}-35^{\circ} \mathrm{C}$, suhu optimal untuk perkembangan telur antara $30^{\circ} \mathrm{C}-32^{\circ} \mathrm{C}$ dan untuk larva, pupa dan dewasa antara $27^{\circ} \mathrm{C}-30^{\circ} \mathrm{C}$. Serangga betina dapat menggerek buah kopi antara suhu $20^{\circ} \mathrm{C}-33^{\circ} \mathrm{C}$, pada suhu $15^{\circ} \mathrm{C}$ dan $35^{\circ} \mathrm{C}$ serangga betina gagal menggerek buah kopi atau mampu menggerek buah kopi tapi tidak bertelur (Jaramilo et al.,2009).

Pengendalian dalam upaya menurunkan intensitas serangan hama $H$. hampei dilakukan dengan sanitasi sangat efektif. Di Brazil, tindakan sanitasi dilaporkan juga sangat efektif untuk mengendalikan hama PBKo (Wiryadiputra, 2007). Cara lain juga dilakukan dengan memutus daur hidup $H$. hampei, seperti memetik buah, yaitu mengawali panen dengan memetik semua buah masak yang terserang $H$. hampei maupun tidak 15 - 30 hari menjelang panen besar. Metode lelesan juga dilakukan yaitu pemungutan semua buah kopi yang jatuh di tanah baik terhadap buah terserang maupun buah tidak terserang. Pemangkasan pada tanaman kopi ditujukan untuk menghindari kelembaban yang tinggi, memperlancar aliran udara sehingga proses penyerbukan dapat berlangsung secara intensif, membuka kanopi agar tanaman mendapat penyinaran merata guna merangsang pembungaan, dan membuang cabang tua yang kurang produktif atau terserang hama atau penyakit sehingga hara dapat didistribusikan kecabang muda yang lebih produktif (Kadir, Ramlan, Nurjanani, Sjafarudin, dan Taufik, 2010).

Tujuan penelitian ini adalah untuk mengetahui jenis hama utama tanaman kopi dan produksi pada perkebunan kopi liberika tungkal komposit (coffea sp.) di kecamatan Betara kabupaten Tanjung Jabung Barat.

Penelitian ini diharapkan dapat memberikan informasi spesifik terkait hama utama tanaman kopi liberika tungkal komposit pada perkebunan kopi liberika tungkal komposit (coffea sp.) di kabupaten Tanjung Jabung Barat, sehingga dapat dicari metode pengendalian dari serangan hama tersebut.

\section{METODE PENELITIAN}

Penelitian ini dilaksanakan pada bulan Agustus sampai bulan September 2016 di Parit Tomo dan Parit Panglong Kelurahan Mekar Jaya serta desa Serdang Jaya, kecamatan Betara kabupaten Tanjung Jabung Barat provinsi Jambi. Bahan yang digunakan dalam penelitian ini adalah buah kopi yang berasal dari tanaman kopi Libtukom yang berumur 3-4 tahun. Alat yang di gunakan dalam penelitian ini adalah alat tulis dan kamera digital.

Pengambilan data dalam penelitian ini menggunakan metode survei. Survei dilakukan pada petani sampel yang melakukan usaha tanaman kopi Libtukom. Data yang dikumpulkan dalam penelitian ini dibagi menjadi dua jenis, yaitu data primer dan data sekunder.

Data primer mencakup jumlah produksi kopi libtukom, jumlah kopi yang terserang hama, jenis hama yang menyerang kopi libtukom. Data sekunder diperoleh dari instansi terkait seperti BPTP Provinsi Jambi, Dinas Pertanian kabupaten Tanjung Jabung Barat, kantor kecamatan dan kantor kepala desa. 
Jurnal Media Pertanian Vol. 2 No. 1 Tahun 2017 Hal. 1 - 9

Media Komunikasi Hasil Penelitian dan Review Literatur Bidang Ilmu Agronomi ISSN $2503-1279$

Responden dalam penelitian ini adalah petani kopi Libtukom yang telah berusaha tani kopi lebih dari 10 tahun, yang dipilih secara sengaja (purposive). Kelompok tani kopi di kecamatan Betara sebanyak 10 kelompok, khususnya di kelurahan Mekar Jaya.Pengambilan tanaman sampel dengan metode purposive sampling untuk mengetahui populasi yang mana ingin diteliti, dan kemudian menggunakan metode Simple Random Sampling.

Menurut Winarno (1994) bila populasi cukup homogen serta populasi dibawah 100 dapat di gunakan sampel sebanyak $50 \%$, bila populasi di atas 100 dapat diambil sebesar $15 \%$ dan sampel manusia hendaknya diatas 30 orang. Dari 3 kelompok tani diambil sampel sebanyak 40 orang. Untuk melihat tingkat serangan hama dan intensitasnya dilakukan pengamatan secara visual terhadap buah kopi pada setiap pohonnya, maka diambil sampel pohon kopi Libtukom sebanyak 50 pada masingmasing daerah pengamatan.

Data yang diperoleh dari hasil penelitian disederhanakan dengan cara ditabulasi lalu dihitung persentasenya menggunakan microsoft excel 2007. Data kemudian dianalisis secara deksriptif baik kualitatif maupun kuantitatif untuk melihat sebaran hama yang menyerang kopi Libtukom di daerah penelitian.

Peubah yang diamati adalah gejala serangan pada buah, daun, dan batang, jenis hama dan intensitas serangan yang menyerang tanaman, serta produksi kopi Libtukom. Intensitas serangan dihitung dengan menggunakan rumus di bawah ini.

$$
\text { Intensitas Serangan Hama }=\frac{\sum \text { Buah terserang }}{\sum \text { Buah yang di amati }} \times 100 \%
$$

\section{HASIL DAN PEMBAHASAN Gejala Serangan Pada Buah}

Berdasarkan hasil pengamatan secara fisik dan visual pada buah kopi yang terserang hama, didapatkan hasil ciri-ciri buah kopi antara lain (Gambar 1):

1. Secara umum buah yang terserang hama berwarna hijau dan sebagian berwarna kuning

2. Pada bagian bawah terdapat lubang yang tembus ke dalam biji

Ciri-ciri diatas diperkuat dengan pendapat Tobing et al., (2006) yang menyatakan bahwa serangan pada buah ditandai dengan biji berlubang, warnanya berubah menjadi kuning kemerahan.

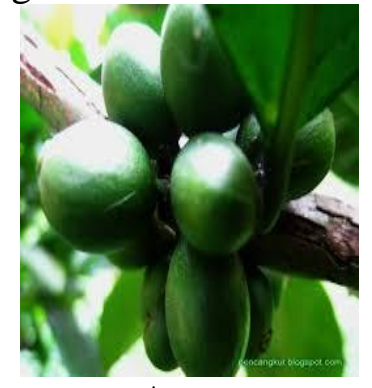

A

Buah Sehat

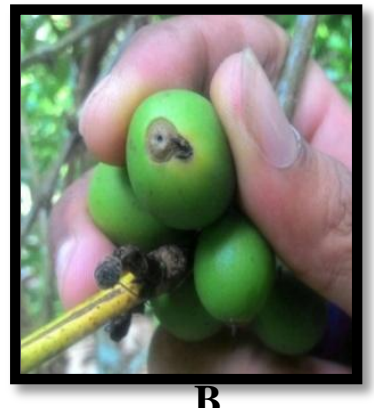

Buah Terserang

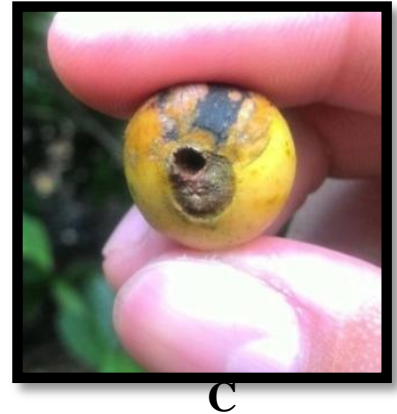

Buah Terserang

Gambar 1. Gejala Serangan Hama penggerek pada buah kopi libtukom 
Jurnal Media Pertanian Vol. 2 No. 1 Tahun 2017 Hal. 1 - 9

Media Komunikasi Hasil Penelitian dan Review Literatur Bidang Ilmu Agronomi ISSN $2503-1279$

\section{Gejala Serangan Pada Daun}

Hasil pengamatan terhadap daun kopi, menunjukkan beberapa gejala serangan hama dengan ciri fisik berikut (Gambar 2).

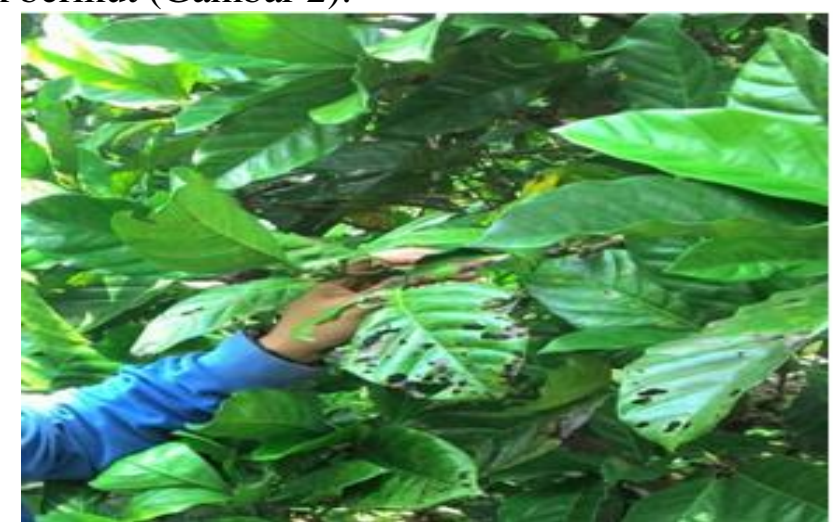

Gambar 2. Gejala Serangan pada Daun Kopi

1. Terdapat lubang-lubang pada bagian daun, tengah dan tepi daun

2. Beberapa daun ditemukan bagian sisi daunnya sudah habis

3. Daun yang dicirikan tersebut pada umumnya berwarna hijau tua kekuningkuningan

4. Lubang yang terbentuk pada daun berukuran relatif beragam, dari lubang kecil, sedang sampai lubang yang cukup besar

\section{Gejala Serangan Pada Batang}

Hasil pengamatan terhadap batang tanaman kopi, menunjukkan beberapa gejala serangan hama dengan ciri fisik berikut ( Gambar 3 ).

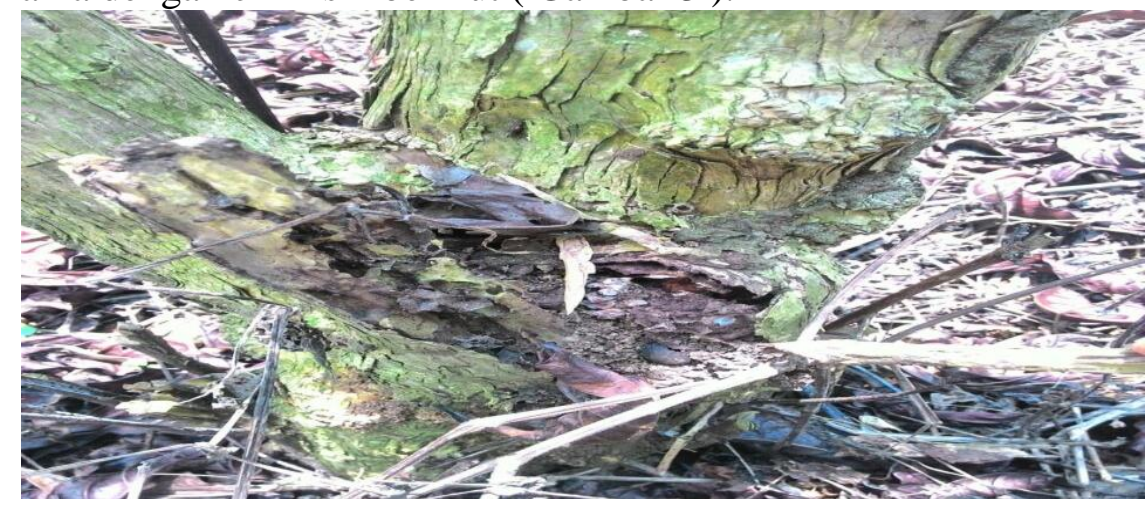

Gambar 3. Gejala Serangan ulat (Zeuzera cofeae) Pada Batang Kopi

1. Batang terlihat kering dan cendrung rapuh

2. Setelah dipotong, batang tersebut berlobang.

\section{Jenis Hama}

Berdasarkan pengamatan visual dan ciri fisik tersebut, kemudian dibandingkan dengan literatur maka disimpulkan bahwa jenis hama yang menyerang tanaman kopi libtukom di daerah penelitian adalah hama jenis serangga Hypothenemus hampei. Hama penggerek buah kopi (Hypothenemus hampei) ini merupakan hama utama yang menyerang tanaman kopi, mulai dari buah muda sampai buah tua. Hal ini diperkuat dengan pernyataan Tobing et al., (2006) yaitu biji yang berlubang merupakan salah satu penyebab utama kerusakan. 
Jurnal Media Pertanian Vol. 2 No. 1 Tahun 2017 Hal. 1 - 9

Media Komunikasi Hasil Penelitian dan Review Literatur Bidang Ilmu Agronomi ISSN $2503-1279$

\section{Intensitas Serangan Pada Buah}

Intensitas serangan pada buah kopi Libtukom di daerah penelitian menunjukkan nilai yang berbeda antar daerah. Rata-rata intensitas serangan di tiga daerah penelitian sebesar $10,33 \%$ atau berkisar antara 9,11\% sampai $10,80 \%$. Data intensitas serangan pada buah kopi Libtukom disajikan pada Tabel 2.

Tabel 2. Rata-rata intensitas serangan penggerek buah kopi di kecamatan Betara

\begin{tabular}{clccc} 
No & Lokasi & $\begin{array}{c}\text { Jumlah Buah yang } \\
\text { diamati (butir) }\end{array}$ & $\begin{array}{c}\text { Jumlah Buah } \\
\text { Terserang (butir) }\end{array}$ & $\begin{array}{c}\text { Intensitas Serangan } \\
\text { pada Buah }(\%)\end{array}$ \\
\hline 1 & Parit Tomo & 128.44 & 11,94 & 9,29 \\
2 & Serdang Jaya & 126.67 & 13,69 & 10,80 \\
3 & Parit Panglong & 51.10 & 4,66 & 9,11 \\
\hline & Rata-Rata & 102,07 & 102.07 & 10.33 \\
\hline
\end{tabular}

Sumber: Data primer yang diolah, Tahun 2016

Dari Tabel 2 dapat dilihat bahwa rataan persentase serangan di daerah penelitian sangat bervariasi. Persentase intensitas serangan hama penggerek buah kopi (PBKo) di daerah penelitian sebesar 10,33\%. Ini menunjukkan bahwa perkembangan hama PBKo di daerah penelitian mampu menyerang buah kopi hingga 10,33\%.

Pracaya (1986), menyatakan bahwa serangga masuk dari ujung buah baik biji yang masih berada di pohon maupun yang telah jatuh ke tanah. Pengendalian harus dilakukan bila persentase serangan $>10 \%$. Tingkat serangan sebesar $20 \%$ dapat mengakibatkan penurunan produksi sekitar $10 \%$.

\section{Produksi Kopi Libtukom}

Produksi kopi libtukom menunjukkan nilai yang berbeda antar daerah. Rata-rata produksi kopi daerah penelitian sebesar $809,13 \mathrm{~kg}$ atau 0,809 ton, sedangkan rata-rata luas lahan yang digunakan dalam budidaya tanaman kopi libtukom di daerah penelitian sebesar 1,22 ha. Masing-masing daerah menunjukkan produksi dan produktivitas tanaman kopi libtukom yang berbeda. Rata-rata produktivitas kopi libtukom di tiga daerah penelitian sebesar 0,66 ton $\mathrm{ha}^{-1}$ tahun $^{-1}$. Data produksi dan produktivitas tanaman kopi libtukom disajikan pada Tabel 3.

Tabel 3. Rata-rata Luas Lahan,Produksi dan Produktifitas Kopi Libtukom di Daerah Penelitian

\begin{tabular}{clccc}
\hline No & Lokasi & Luas Lahan (ha) & $\begin{array}{c}\text { Produksi (ton } \\
\left.\text { tahun }^{-1}\right)\end{array}$ & $\begin{array}{c}\text { Produktifitas (ton ha } \\
\left.\text { tahun }^{-1}\right)\end{array}$ \\
\hline 1 & Parit Tomo & 0,86 & 0,571 & 0,66 \\
2 & Serdang Jaya & 1,46 & 0,964 & 0,66 \\
3 & Parit Panglong & 1,33 & 0,892 & 0,67 \\
\hline & Rata-Rata & 1,22 & 0,809 & 0,66 \\
\hline
\end{tabular}

Sumber: Data primer yang diolah, Tahun 2016

Tabel 3 memperlihatkan bahwa di desa Parit Tomo, Serdang jaya dan Parit Panglong luas lahan 0,86 ha sampai 1,46 ha, produksi 0,571 ton tahun ${ }^{-1}$ sampai 0,964 ton $\operatorname{tahun}^{-1}$ dan produktivitas berkisar antara 0,66 ton $^{-1} \mathrm{tahun}^{-1}$ sampai 0,67 ton ha ${ }^{-1}$ tahun $^{-1}$. 
Jurnal Media Pertanian Vol. 2 No. 1 Tahun 2017 Hal. 1 - 9

Media Komunikasi Hasil Penelitian dan Review Literatur Bidang Ilmu Agronomi ISSN $2503-1279$

Tingkat produksi kopi liberika tergolong kedalam beberapa kategori, produksi kopi tinggi jika 900-1000 $\mathrm{kg}_{\text {tahun }}{ }^{-1}$, sedangkan produksi rendah berkisar antara 400$500 \mathrm{~kg}$ tahun $^{-1}$ (Gusfarina, 2014).

Berdasarkan data pada Tabel 3, rata-rata produksi kopi libtukom didaerah penelitian sebesar $809.13 \mathrm{~kg}$ atau 0.809 ton, produksi ini tergolong kedalam produksi sedang dan mendekati produksi tinggi. Tingginya produksi kopi pada daerah penelitian diduga disebabkan karena varietas kopi libtukom sangat cocok dibudidayakan di daerah gambut. Hal ini sesuai dengan pendapat Gusfarina (2014), yang menyatakan bahwa kopi libtukom merupakan tanaman kopi yang mampu beradaptasi baik di lahan gambut dengan tanaman penaung pohon pinang.

\section{KESIMPULAN DAN SARAN}

\section{Kesimpulan ;}

1. Hama utama yang menyerang buah kopi liberika tungkal komposit (Libtukom) adalah spesies Hypothenemus hampei yang dikenal dengan nama penggerek buah kopi (PBKo). Rata-rata intensitas serangan hama PBKo di kecamatan Betara adalah $10,33 \%$.

2. Produksi kopi libtukom sebesar 0,809 ton tahun $^{-1}$ dengan produktivitas 0,66 ton ha $^{-1} \operatorname{tahun}^{-1}$

\section{Saran :}

Perlu dilakukan upaya pengendalian hama penggerek buah kopi yang ramah lingkungan, karena intensitas serangan hama sudah melewati ambang kendali.

\section{DAFTAR PUSTAKA}

BPS Provinsi Jambi 2014, Jambi Dalam Angka 2014, Biro Pusat Statistik Provinsi Jambi.

Departemen Pertanian. 2002. Musuh Alami, Hama dan Penyakit Tanaman Kopi. Direktorat Perlindungan Perkebunan, Direktorat Jenderal Bina Produksi Perkebunan, Jakarta: Departemen Pertanian

Dirjen Perkebunan. 2014. Statistik Perkebunan Indonesia 2013-2015. Direktorat Jendral Perkebunan: Jakarta

Gusfarina D.S. 2014. Mengenal Kopi Liberika Tungkal Komposit (Libtukom) Balai Pengkajian Teknologi Pertanian (BPTP): Jambi

Jaramillo, J., Olaye, A. C., Kamonjo, C., Jaramillo, A., Vega, F. E., Poehling, M., Borgemeister, C. (2009) . Thermal Tolerance of the Coffee Berry Borer Hypothenemus hampei: Predictions of Climate Change Impact on a Tropical Insect. Pest. Plos One. 4 (8): 64-87.

Kadir, S. Ramlan, Nurjanani, M. Sjafarudn, dan M. Taufik, 2010. Kajian Teknologi Pemangkasan pada Tanaman Kopi. http://www.sulsel.litbang.deptan.go.id. (diunduh 23 Maret 2016)

Pusat Penelitian Kopi dan Kakao Indonesia (PPKKI). 2006. Pedoman Teknis Budi Daya Tanaman Kopi. Indonesia Coffee and Cacao Research Institute Jember, Jawa Timur

Pracaya, 1986. Hama Penyakit Tanaman. Penebar Swadaya. IKAPI

Raharjo, B. T. 2013, Analisis Penentu Ekspor Kopi Indonesia. Jurnal Ilmiah 
Jurnal Media Pertanian Vol. 2 No. 1 Tahun 2017 Hal. 1 - 9

Media Komunikasi Hasil Penelitian dan Review Literatur Bidang Ilmu Agronomi ISSN $2503-1279$

Mahasiswa FEB, Vol. 1, No. 1

Tobing, M.C., D. Bakti, A. Sutanto dan H. Saragih. 2006. Uji penggunaan perangkap feromon dan jala untuk pengendalian Oryctes rhinoceros (Coleoptera: Scarabaeidae) pada tanaman kelapa sawit. Kerjasama Dept. HPT Fakultas Pertanian USU dengan Pusat Penelitian Kelapa Sawit Marihat.

Wiryadiputra, S. 2007. Pengelolaan Hama Terpadu Pada Hama Penggerek Buah Kopi, Hypothenemus hampei (Ferr.) dengan Komponen Utama pada Penggunaan Perangkap Brocap Trap. Pusat Penelitian Kopi dan Kakao Indonesia Jember, Jawa Timur.p.2-9.

Wiryadiputra S. 2012. Keefektifan insektisida cyantraniliprole terhadap hama penggerek buah kopi (Hypothenemus hampei) pada kopi arabika. Jurnal Pelita Perkebunan No 28 Vol (2) Hal 100-110 